\title{
Clumping in Device or Device Ingredient
}

National Cancer Institute

\section{Source}

National Cancer Institute. Clumping in Device or Device Ingredient. NCI Thesaurus. Code C63275.

Problem associated with the aggregation of particles into irregular masses. 